\title{
Yaprakbitlerinden elde edilen bazı fakültatif endosimbiyont türlerin moleküler karşılaştırılması
}

\author{
Molecular comparison of some facultative endosymbiotic species obtained from \\ aphids
}

\section{Gül SATAR}

Çukurova Üniversitesi, Biyoteknoloji Araştırma ve Uygulama Merkezi, Balcalı, ADANA

Sorumlu yazar (Corresponding author): G. Satar, e-posta (e-mail): satarg@cu.edu.tr

\section{MAKALE BİLGİSİ}

Alınış tarihi 15 Ocak 2020

Düzeltilme tarihi 05 Mart 2020

Kabul tarihi 05 Mart 2020

\section{Anahtar Kelimeler:}

Aphididae

Candidatus

Genetik ilişki

Sekonder simbiyontlar

Arsenophonus

\begin{abstract}
ÖZ
Yaprakbitleri tarımsal alanlarda pek çok konukçu bitkide yaptığı zarardan dolayı önemlidir. Yaprakbitlerinin konukçu bitki seçimi, üreme, ilaçlara dayanıklılık gibi biyolojik aktivitelerinde anahtar öneme sahip endosimbiyotlar mevcuttur. Zararlının biyolojisini bu kadar etkileyen endosimbiyontlar üzerine ülkemizde pek çalışma yoktur. Bu nedenle yürütülen bu çalışmada da Adana ilinde farklı lokasyon ve bitkiler üzerinde toplanan yaprakbiti türlerindeki endosimbiyontlar üniversal bir primer ile tespit edilmiștir. Elde edilen endosimbiyontların filogenetik ilişkisi Maximum Likelihood metoduna göre ortaya konulmuştur. Yapılan analizler sonucunda yaprakbiti türleri üzerinden Buchnera aphidicola, Arsenophonus, Candidatus Hamiltonella defensa, Ca. Fukatsuia symbiotica, Ca. Serratia symbiotica endosimbiyont türleri elde edilmiştir. Filogenetik ağaç üzerinde tüm endosimbiyont türler yüksek Bootstrap değerleriyle birbirlerinden ayrılmıștır. Aphis craccivora'nın Robinia pseudoacacia'ya özgü haplotip geliştirmesinde etken olduğu düşünülen fakültatif Arsenophonus bu çalışmada da belirlenmiştir.
\end{abstract}

\section{ARTICLE INFO}

Received 15 January 2020

Received in revised form 05 March 2020

Accepted 05 March 2020

\section{Keywords:}

Aphididae

Candidatus

Genetic relation

Secondary symbionts

Arsenophonus

\begin{abstract}
Aphids are important in agricultural areas due to the damage they do to many host plants. The endosymbionts play a key role in the biological activities of aphids such as host plant selection, reproduction, and drug resistance. Very few studies on endosymbionts that affect the biology of the pest so much were conducted in our country. In this study, endosymbionts in aphid species collected on different locations and plants in Adana province were determined with a universal primer. The phylogenetic relationship among obtained endosymbionts was determined according to the Maximum Likelihood method. As a result of the analysis, Buchnera aphidicola, Arsenophonus, Candidatus Hamiltonella defense, Ca. Fukatsuia symbiotica, $C a$. Serratia symbiotica, endosymbiont species obtained on the different aphid populations. All endosymbiont species on the phylogenetic tree were separated from each other by high Bootstrap values. The facultative Arsenophonus, which is thought to be a factor in the development of specific haplotype to Aphis craccivora on Robinia pseudoacacia was also identified in this study.
\end{abstract}

\section{Giriş}

Yaprakbitleri tarımsal üretimde tahıl, meyve ağaçları, turunçgiller, sebze ve yabancı otlar üzerinde önemli bir zararlı grubunu oluşturmaktadır (Baumann ve ark. 1995). Bitkilerde doğrudan emgi zararının yanında fumajine neden olarak ve en önemli zararlarından biri olan virüslere vektörlük yaparak da zarar oluşturmaktadırlar. Bugüne kadar 5100 yaprakbiti türü (Hemiptera: Aphididae) 11 alt familyada tanılanmıştır. Bu yaprakbitlerinin neredeyse hepsinde hücreler arası simbiyont bakteriler mevcuttur (Fukatsu 2001; Blackman ve Eastop 2018; Favret 2018). Bu simbiyontlar Buchnera aphidicola Munson ve ark. 1991 (Enterobacteriales: Enterobacteriaceae) gibi obligat olabilmektedir. Obligat mutalistik simbiyont olan B. aphidicola (Nikoh ve ark. 2010) yaprakbitlerinin fizyolojilerinin işleyebilmesinde görevlidir ve yaprakbitlerinde üremenin gerçekleşmesi bu endosimbiyonta bağlıdır (Baumann ve ark. 1995; Chen ve ark. 2009; Baldo ve ark. 2006; Simon ve ark. 2011; Satar 2019). Yaprakbitlerinde B. aphidicola'nın olmaması durumunda yaprakbitleri için gerekli bazı amino asit ve vitaminleri alamamasından dolayı dwarf fenotip dediğimiz cüce yaprakbitleri oluşumu, gelişimde yavaşlama, yavru verememe 
veya yavru veriminde azalma görülmektedir (Douglas 1998; Akman Gündüz ve Douglas 2008). Diğer bir grup ise yaprakbitlerinde kalıtsal olarak aktarılan ama konukçunun üreme ve gelişimi için gerekli olmayan bazen horizontal olarak aktarılabilen bakteriyel fakültatif ya da sekonder olarak tanımlanan (Degnan ve ark. 2010) Rickettsia, (Rickettsiales: Rickettsiaceae), Candidatus Hamiltonella defensa, Ca. Regiella insecticola ve $\mathrm{Ca}$. Serratia symbiotica (Enterobacteriales: Enterobacteriaceae) (Peccoud ve ark. 2013) gibi simbiyontlara sahiplerdir. Sekonder endosimbiyontlar avc1-av, parasitoid-av ilişkisi (Tsuchida ve ark. 2010; Vorburger ve ark. 2010; Telesnicki ve ark. 2012; Martine ve ark. 2013), böceklerin diş koşullara adaptasyonunda (Russell ve Moran 2006), insektisitlere dayanıkl1lıkta önemlidirler. Örneğin, $C a$. Hamiltonella defensa, parazitoitlere karşı, Regiella insecticola bezelye afidinde fungal etmen Pandora neoaphidis' e karşı yaprakbitlerinde dayanıklılık sağlamaktadır (Burke ve ark. 2009). Bezelye afidinde, Acyrthosiphon pisum (Harris), fakültatif simbiyontlar PASS (pea aphid secondary symbiont) ya da PAR (pea aphid rickettsia) olmadan yüksek sicaklıklarda üreme oranı \%35'lerden \%6'nın altına düşmektedir (Chen ve ark. 2000). Bu ilişkilerin ortaya konmasında en çok kullanılan yöntem moleküler yöntemlerdir. Hangi endosimbiyotun hangi yaprakbiti türünde var olduğu ve böceklerin hangi koşullara göre bu adaptasyonu geliştirdiklerini anlamak için bu endosimbiyonların varlığının tespiti önemlidir.

$\mathrm{Bu}$ çalışma farklı yaprakbiti tür ve popülasyonlarında bir üniversal proteobacterial primer kullanılarak elde edilebilecek farklı endosimbiyont türlerini belirlemek ve elde edilen türlerin 16S rRNA bölgesindeki farklılıklarını ortaya koymak amacıyla ele alınmıştır. $\mathrm{Bu}$ çalışma Adana ilinde yaprakbitlerinin endosimbiyontlarının belirlenmesi ile ilgili yürütülen ilk çalışma niteliğindedir.

\section{Materyal ve Yöntem}

\subsection{Arazi çalışmaları}

Çalışmada kullanılmak üzere Adana ilinde farklı bitkiler üzerinden yaprakbiti örnekleri toplanmıştır. Bu amaçla Temmuz (2017)-Şubat (2018) ayları arasında arazi çıkışları yapılmıştır (Çizelge 1). Arazide kanatlı ve kanatsız ergin yaprakbitleri firça yardımıla eppendorf tüplerde \%96 alkol içerisine aktarılarak laboratuvara buz içerisinde getirilmiştir. Her örneğin toplanma tarihi, bitki ve toplandığı yer kaydedilmiştir. Örnekler kullanılacakları zamana kadar -80'de muhafaza edilmiştir. Yaprakbiti teşhisleri Dr. Işı1 ÖZDEMIR tarafından gerçekleştirilmiştir.

\subsection{Moleküler Çalı̧̧malar}

\subsubsection{DNA İzolasyonu}

Yaprakbilerinde endosimbiyontları belirlemek için 24 popülasyonda (Çizelge 1) 45 örnekten DNA izolasyonun yapılmıştır. DNA'ları elde etmek için QIAGEN'nin DNAeasy Blood \& Tissue Kiti (QIAGEN, 69504) kullanılmış ve izolasyon, kitin metodunda birkaç modifikasyon yapılarak tek bir kanatsız yaprakbiti ergininden gerçekleştirilmiştir. Çalışmada Liu ve ark. (2013) ve Marutani-Hert (2011)'nın farklı böceklerde farklı endosimbiyotları belirlemek amaciyla kullandığı 16S rRNA bölgesini hedefleyen üniversal primerler 16SF (5'-AGAGTTTGATCATGGCTCAGATTG-3') ve 16SR (5'-TACCTTGTTACGACTTCACCCCAG-3') kullanılmıştır. Her bir PCR reaksiyonunda $25 \mu \mathrm{l}$ toplam miktar için; $3 \mu \mathrm{l}$ DNA, $17.25 \mu 1 \mathrm{H}_{2} \mathrm{O}, 2.5 \mu 1$ 10X Dream taq green buffer, $0.5 \mu 1$ dNTP (final konsantrasyonda; $0.2 \mathrm{mM}$ ), her bir primerden 0.75 $\mu 1$ ve $0.25 \mu 1$ Taq (Dream Taq DNA polymerase) karışımları kullanılarak gerçekleştirilmiştir. Thermocycler (Applied Biosystems $\mathrm{AB}$ (Veriti)) ise; $95^{\circ} \mathrm{C}^{\prime} \mathrm{de} 3 \mathrm{dk}, 95^{\circ} \mathrm{C}$ 'de $15 \mathrm{sn}$, $55^{\circ} \mathrm{C}^{\prime}$ de $15 \mathrm{sn}, 72^{\circ} \mathrm{C}$ 'de 30 sn 35 döngü ve $72^{\circ} \mathrm{C}^{\prime}$ de $7 \mathrm{dk}$ olarak ayarlanmıştır. Elde edilen PCR ürünü \%1'lik agaroz jelde 50 volt $100 \mathrm{~mA}$ 'da $60 \mathrm{dk}$ koşturmaya takiben Etidium bromürde y1kanmasından sonra jel görüntüleme sitemi ile görüntülenmiştir. Pozitif sonuç veren örnekler gen dizileme için ticari bir firmaya gönderilmiştir.

\subsubsection{Dizi analizi ve sonuçların değerlendirilmesi}

Gen dizileme sonucunda elde edilen nükleotid dizileri National Center for Biotechnology Information'ın Blast analiz programina girilerek gen bankasındaki genlerle karşılaştırılmıştır. $\mathrm{Bu}$ sayede elde edilen gen bölgeleri doğrulanmış ve gen bankasında bulunan yaprakbiti türlerinden elde edilmiş farklı endosimbiyotlara ait benzer gen bölgeleri de bu çalışma için referans genler olarak çalışmaya dahil edilmiştir.

Doğrulaması yapılan gen bölgeleri "Molecular Evolutionary Genetics Analysis (Mega 6.0)" programı (Felsenstein 1985) ile görüntülenmiştir. Gen dizilemesi yapılan her bir örnek için gen bölgelerinin dizilimleri her iki yönü Mega 6.0 programında üst üste getirilip hizalamış ve Finch TV programında görüntülenmiştir. Bu sayede elde edilen dizilimlerin temizliği ve doğruluğu çift yönlü olarak yapılıp doğrulanmıştır. Gen bankasında alınan referans genler ile bu çalışmadan elde edilen gen dizilimleri arasındaki filogenetik ilişkilerin ortaya konulması için en uygun parametre modeli Mega 6.0 programinda belirlenmiştir. Elde

Çizelge 1. Filogenetik çalı̧̧malarda kullanılan farklı obligat ve fakültatif simbiyotların tespit edildiği yaprakbitlerinin toplandığı yerler, tarih, konukçu bitki ve endosimbiyot türleri.

Table 1. The locations, collection date, and host plant of aphid species having different obligate and facultative endosymbionts used in phylogenetic studies and endosymbiont species.

\begin{tabular}{|c|c|c|c|c|c|}
\hline No & Tarih & Yer & Konukçu bitki & Aphid türü & Endosimbiyont tür \\
\hline 1 & 07.09 .2017 & Çiftehan & Malus communis $L$. & Aphis pomi De Geer & Ca. Fukitima simbiotica \\
\hline 2 & 07.09 .2017 & Çiftehan & Robinia pseudoacacia $\mathrm{L}$. & Aphis craccivora Koch & Arsenophonus \\
\hline 3 & 13.09.2017 & Balcalı & R. pseudoacacia $\mathrm{L}$. & A. craccivora & Arsenophonus \\
\hline 4 & 20.09.2017 & Akkaya- Feke & Phaseolus vulgaris $L$. & Aphis fabae Scopoli & Ca. Hamiltonella defensa \\
\hline 5 & 20.09 .2017 & Gaffar Uşağı-Feke & Zea mays $L$. & $\begin{array}{l}\text { Rhopalosiphum maidis } \\
\text { (Fitch) }\end{array}$ & $\mathrm{Ca}$. Serratia symbiotica \\
\hline 6 & 24.02 .2018 & Zeytinli & Capsella bursa-pastoris (L.) & A. craccivora & Buchnera aphidicola \\
\hline
\end{tabular}


edilen en uygun model Kimura 2-parametresi olmuştur. $\mathrm{Bu}$ model yardımıyla Maximum likelihood metodu kullanılarak filogenetik ilişkiler ortaya konulmuştur (Tamura ve ark. 2013). Boostrap konsensüs ağacı 1000 tekrara göre yapılmıştır (Nei ve Kumar 2000). Filogenetik analizde endosimbiyontlara ait referans genler ve diş grup olarak Escherichia coli (J01859.1) geni gen bankasından (NBCI) alınarak kullanılmıştır. Elde edilen endosimbiyont türlerin nükleotid dizilimleri arasındaki farklılıkları göstermek için Genedoc programı kullanılmıştır.

\section{Bulgular ve Tartışma}

Adana ilinde Aphis craccivora Koch, Aphis fabae Scopoli, Aphis pomi De Geer ve Rhopalosiphum maidis (Fitch) (Hemiptera:Aphididae) yaprakbiti türlerinden elde edilen endosimbiyontlar referans genlerle karşılaştırılmıştır ve filogenetik ağaç Maximum-Likelihood metoduna göre oluşturulmuştur. Analizlerde 620 bp'lik 16S rRNA bölgesi çalışılmıştır. Toplam 45 örnekle çalışma yürütülmüş bunların 40'inda $B$. aphidicola bulunurken, diğer beş örnekte ise farklı fakültatif endosimbiyont türler elde edilmiştir. B. aphidicola A. craccivora, A. fabae, A. gossypii Glover, A. pomi, Myzus ceraci
(F.), M. persicae (Sulzer) ve $R$. maidis türleri üzerinden saptanmıştır. Yedi yaprakbiti üzerinden her yaprakbiti türüne özgü B. aphidicola suşları elde edilmiş aradaki farklılık Satar (2019) tarafindan ortaya konulmuştur. Neredeyse tüm yaprakbiti türlerinde saptanan $B$. aphidicola böceğin fizyolojisinin, özellikle üreme ve beslenmesinin sürebilmesi için elzemdir (Douglas 1998) ve bu çalışmada daha fazla elde edilmesi normal görülmüştür.

Çalışmadaki diğer beş örnekten Arsenophonus, Candidatus Hamiltonella defensa, $C a$. Fukatsuia symbiotica, $C a$. Serratia symbiotica fakültatif endosimbiyont türleri elde edilmiştir (Çizelge 1). Türlere ait farklı nükleotid dizilimine sahip beş örneğin dizilimleri NCBI gen bankasına MN913498-502 kodları ile yüklenmiştir (Şekil 1). Arsenophonus sadece $A$. craccivora üzerinde, $C a$. S. symbiotica $R$. maidis üzerinde, $C a$. Hamiltonella defensa $A$ fabae, $C a$. Fukatsui symbiotica ise $A$. pomi üzerinden tespit edilmiştir (Çizelge 1). Aphis craccivora'nın endosimbiyontları üzerine yapılan çalışmalar göstermiştir ki Arsenophonus simbiyontu Robinia sp. konukçu bitkilerinden toplanan A. craccivora'lar üzerinde yaygın iken,

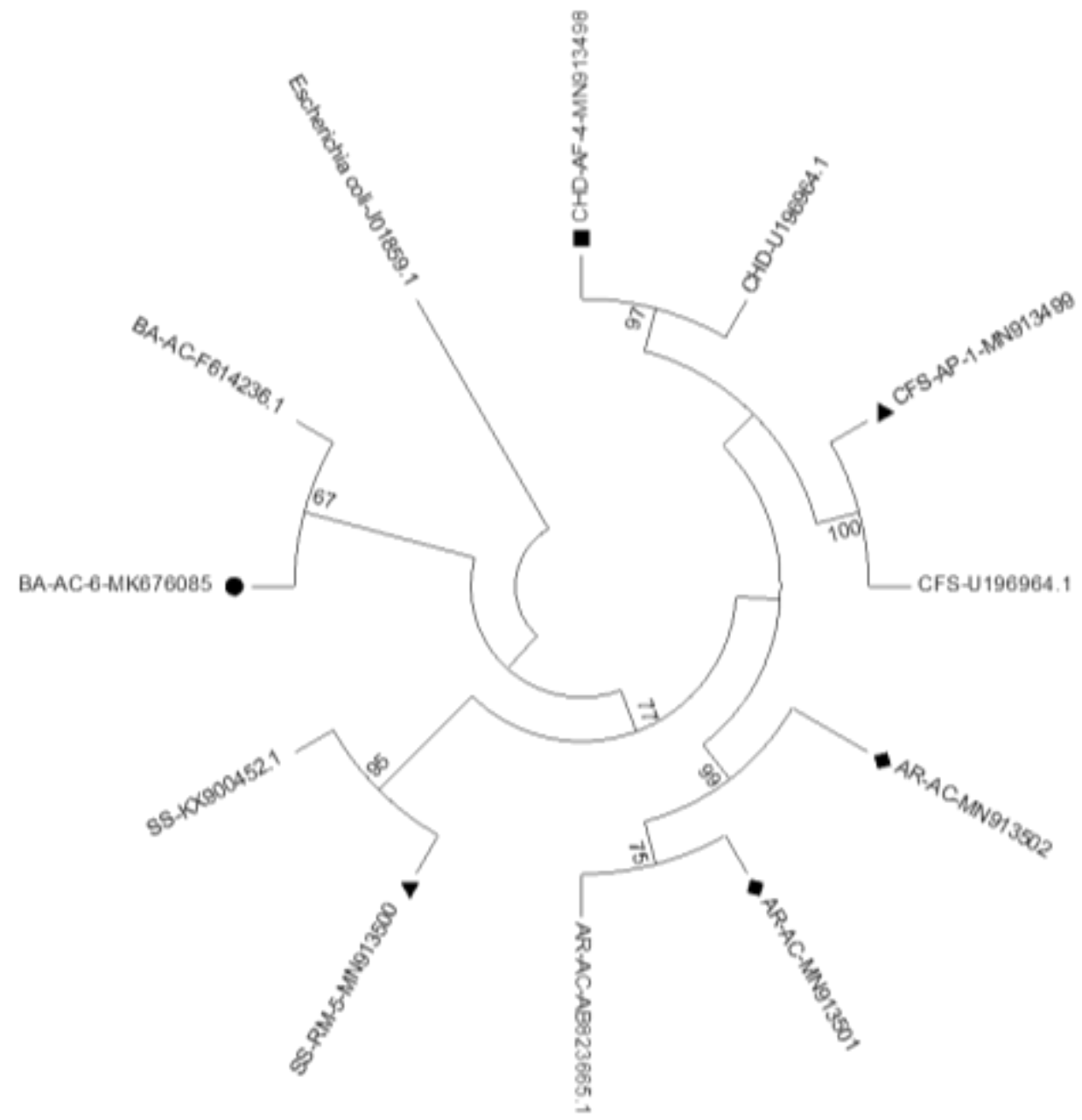

Şekil 1. Farklı yaprakbiti türleri üzerinde saptanan endosimbiyontların filegenetik ilişkileri (BA: Buchnera aphidicola, AR: Arsenophonus, CHD: Candidatus Hamiltonella defensa, CFS: Candidatus Fukatsuia symbiotica, SS: Serratia symbiotica, AC: Aphis craccivora, AF: Aphis fabae, AP: Aphis pomi, RM: Rhopalosiphum maidis ve endosimbiyontlara ait referans numaralarylla verilmiş referans genler).

Figure 1. Filegenetic relationships of endosimbionts detected on different aphid species (BA: Buchnera aphidicola, AR: Arsenophonus, CHD: Candidatus Hamiltonella defensa, CFS: Candidatus Fukatsuia symbiotica, SS: Serratia symbiotica, AC: Aphis craccivora, AF: Aphis fabae AP: Aphis pomi, RM: Rhopalosiphum maidis and Reference gene numbers). 
yonca üzerindeki $A$. craccivora'lar da ise Hamiltonella'nın yaygın olduğu ve $A$. craccivora'ların bu bitkilere özelleşmiş muhtemel haplotiplerinin gelişiminde bu fakültatif simbiyontların etkili olduğu bildirilmiştir (Brady ve ark. 2013; Brady ve ark. 2014). Bu çalışmada da hem Çiftehan hem de Balcalı'dan Robinia pseudoacacia üzerinde toplanan $A$. craccivora'larda fakültatif Arsenophonus'un saptanmış olması bu çalışmaları destekler niteliktedir. Çiftehan $1000 \mathrm{~m}$ rakım, Balcalı $127 \mathrm{~m}$ rakımda olmasına rağmen iki farklı coğrafik bölgeden toplanan örneklerin nükleotid dizilimlerinde farklılık saptanmamıştır (Şekil 2). Ancak Pozantı'dan aynı bitkiden toplanan örnekte Arsenophonus yerine B. aphidicola elde edilmiştir.

Çalışmada saptanan B. aphidicola ve Arsenophonus hariç diğer endosimbiyont türlerin hepsinin parazitoit ve predatörlere karşı yaprakbitlerinde savunma mekanizmasının çalışmasıyla ilişkili olduğu (Tsuchida ve ark. 2010; Vorburger ve ark. 2010; Telesnicki ve ark. 2012; Martine ve ark. 2013) düşünüldüğünde bu popülasyonlar üzerinde muhtemel bir doğal düşman

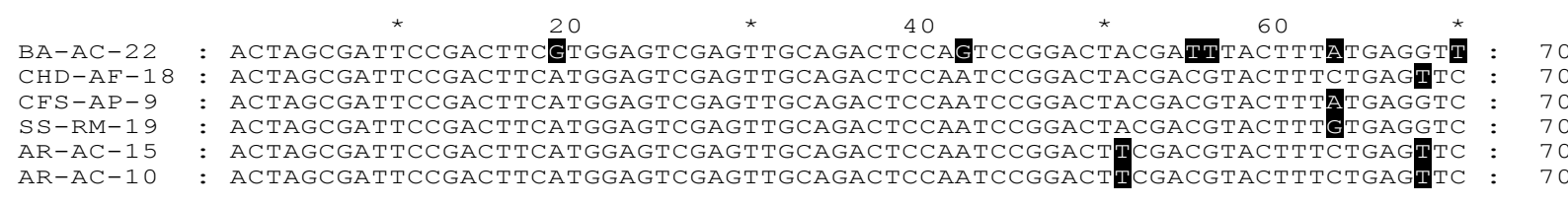

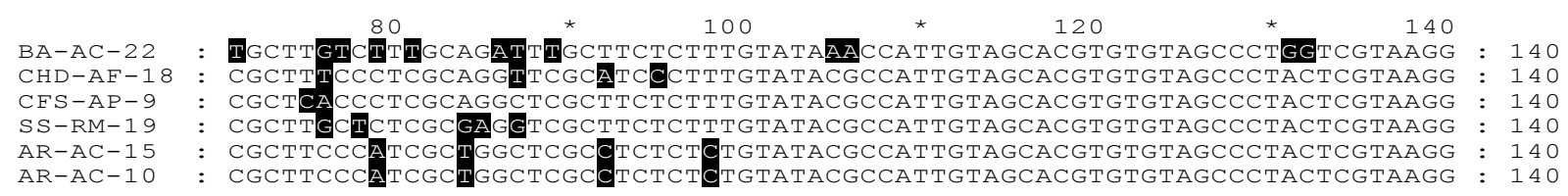

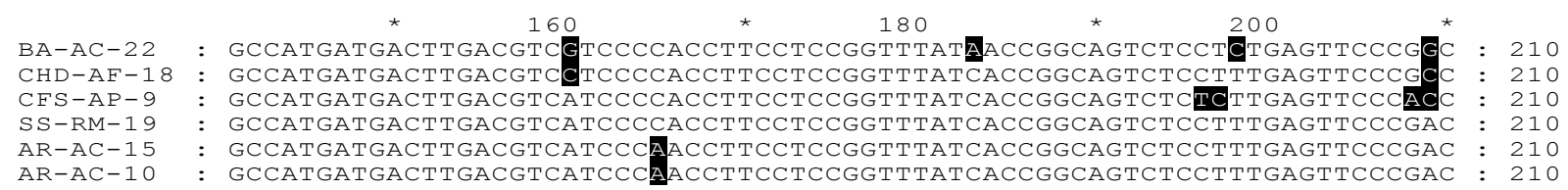

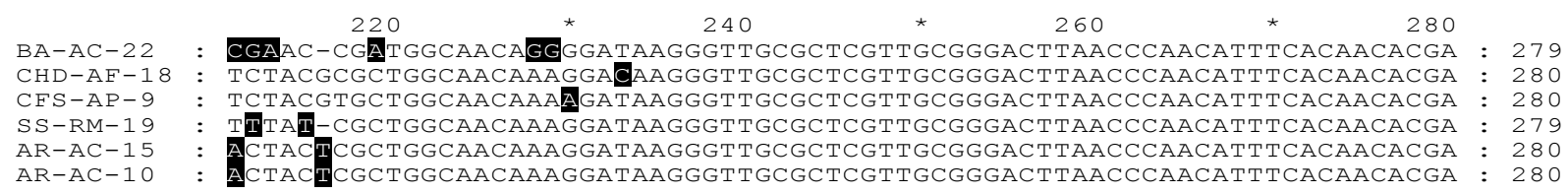

$\mathrm{BA}-\mathrm{AC}-22$ $\mathrm{CHD}-\mathrm{AF}-18$ CES $-\mathrm{AP}-9$ $\mathrm{SS}-\mathrm{RM}-19$ AR $-A C-15$ $\mathrm{AR}-\mathrm{AC}-15$
$\mathrm{AR}-\mathrm{AC}-10$

$\mathrm{BA}-\mathrm{AC}-22$ $\mathrm{CHD}-\mathrm{AF}-18$ CFS-AP- 9 SS-RM- 19 AR-AC-1 5 AR $-\mathrm{AC}-10$
300

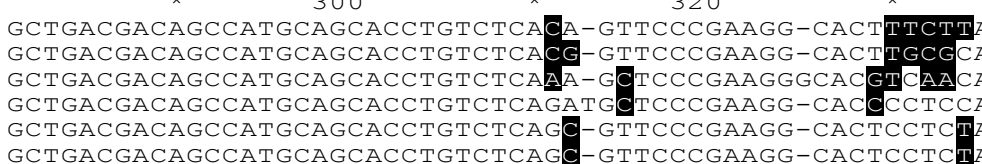

360

380

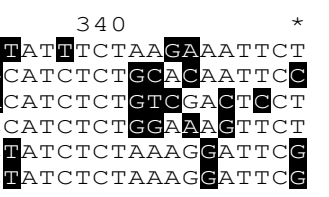

$400 \quad 420$

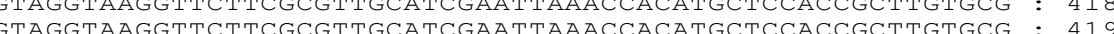
CTGGATGTCAAGAgTAGgTAAGGTTCTTCGCGTTGCATCGAATTAAACCACATGCTCCACCGCTTGTGCG: 418 CTGGATGTCAAGAGTAGGTAAGGTTCTTCGCGTTGCATCGAATTAAACCACATGCTCCACCGCTTGTGCG : 418 CTA

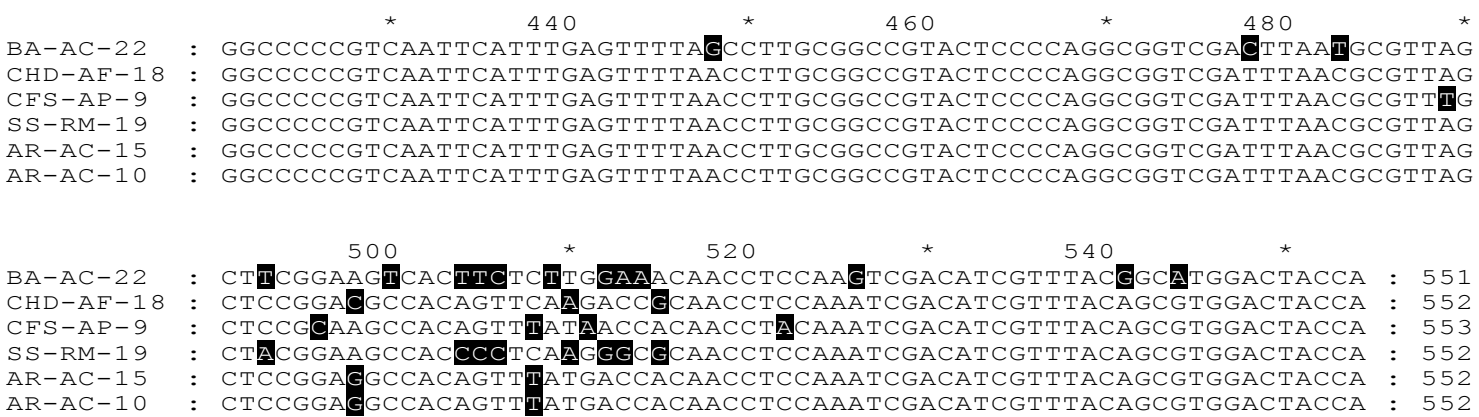

Şekil 2. Farklı yaprakbiti türlerinden elde edilmiş olan farklı endosimbiyont türlerin baz düzeyinde karşılaştırılması.

Figure 2. Comparison of different endosimbiont species obtained from different aphid species at the base level. 
baskısı olduğu ve bu nedenle bu endosimbiyontların miktarının fazla olmasından dolayı diğer örneklerle aynı anda yapılan PCR amplifikasyonlarından farklı endosimbiyontların elde edildiği düşünülmektedir. Ca. Hamiltonella defensa ile infekteli Acyrthosiphon pisum (Hemiptera: Aphididae) yaprakbiti parazitoitleri Aphidius ervi ve Aphidius eadyi (Hymenoptera: Braconidae)'ye karşı hayatta kalmada daha başarılı olduğu saptanmıştır (Degnan and Moran 2009). Benzer sonuçlar A. pisum üzerinde Lysiphlebus fabarum, A. craccivora üzerinde Binodoxys communis, B. koreanus, Lysiphlebus orientalis ve Aphidius colemanii Viereck için de saptanmıştır (Asplen ve ark. 2014). Çukurova bölgesinde de bu yaprakbiti türleri mevcut olup (Uygun ve ark. 2001) bu türler üzerinde yaygın olan Aphidus (Aphidius colamani, A. ervi), Lysiphlebus (Lysiphlebus fabarum, L. confusus), Binodoxy (Binodoxy angelicae, B. acalaphae) cinsine bağlı türlerin (Satar ve ark. 2014; Satar ve ark. 2019) salım çalışmaları ya da doğada destekleme çalışmaları yapılırken bu endosimbiyontların varlığının tespiti önemli olacaktır. Böylece bölgede evrimsel süreçte parazitoitlere karşı yaprakbitlerinin geliştirdiği savunma mekanizmaları veya yaprakbiti-parazitoit- konukçu bitki arasında oluşan trofik ilişkilerin daha anlaşılır olmasına katkı sağlanabilir. Özellikle ticari olarak da üretilip satılan $A$. colemani'nin salındığı alanlarda başarısızlık durumlarında da problem endosimbiyontlar ile ilişkilendirilebilir. Örneğin, Prado ve ark. (2015) serada yaprakbitlerinde endosimbiyont varlığında yaprakbitlerinin A. colemani' ye dayanıklı olabileceklerini, ya da infekteli ve infektesiz konukçu yaprakbitlerini ayıramayan parazitoidin yumurtalarını ve enerjilerini boşa harcayabileceklerini belirtmiştir.

Candidatus Serratia symbiotica parazitoitlere karşı koruma sağlamasının yanı sıra 1sı şokuna karşı bakteriyositilerdeki simbiyontları korur, ayrıca konukçu yaprakbiti için bazı aminoasitleri üreterek yaprakbitinin Buchnera'ya bağımlılı̆̆ını azaltarak beslenmede rol oynamaktadır (Burke ve ark. 2009). Örneğin Cinara cedri (Lachnini)'de tryptophan biyosentezinde S. sybiotica'nın görev aldığ 1 Pe'rez-Brocal ve ark. (2006) tarafından saptanmıştır. $\mathrm{Bu}$ çalışmada Adana'nın yayla kesiminde bulunan Feke ilçesinden $R$. maidis popülasyonunda $\mathrm{Ca}$. S. simbiyotica saptanmıştır. Özellikle küresel ısınmanın etkisini artırdığı günümüzde oluşabilecek ani sıcaklık değişimlerine karşı popülasyon içerisinde bu endosimbiyont türünü barındıran bireylerin varlığı bakteriositler içerisinde bulunan ve yaprakbitlerinin beslenmesinde büyük rol oynayan B. aphidicola'yı koruyarak popülasyonun devamlılığının sağlanması için belki önemli olacaktır. Arsenophonus'un ise henüz yaprakbitlerine olan fenotipik etkisi kesin olarak çözülememiştir. Ancak yaprakbitlerinin konukçu bitkiye özelleşmesinde önemli olduğu düşünülmektedir (Brady ve ark. 2014; Tian ve ark. 2019). Diğer bir çalışmada da popülasyonun genişlemesinde ve yaprakbitinin zarar düzeyinin artmasında etkili olabileceği düşünülmektedir (Wulff ve White 2015).

Çalışmada elde edilen farklı endosimbiyont türlerin birbirleriyle genetik ilişkileri incelendiğinde obligat $B$. aphidicola diğer sekonder endosimbiyontlardan yüksek bir Boostrap değeriyle ayrılmıştır. Sekonder endosimbiyontlar ise 90'1n üzerinde boostrap değerleriyle birbirlerinden ayrılmışlardır (Şekil 1). Patel ve ark. (2019) da bezelye afidi üzerinde $C a$. S. symbiotica, $C a$. H. defensa, $C a$. F. Symbiotica türleriyle Maximum likelihood yöntemi kullanılarak oluşturdukları filogenetik ağaçta bu türlerin 99-100 gibi Bootstrap değerleriyle birbirlerinden ayrıldıklarını saptamışlardır. Çalışmada elde edilen endosimbiyont türlerin nükleotid dizileri karşılaştırıldığında türler arası korunmuş bölgeler olmasına rağmen, pek çok baz farklılığı da saptanmıştır (Şekil 2). Bu korunmuş bölgeler bir çift primerle farklı endosimbiyontların elde edilebileceğini göstermektedir.

Kullanılan üniversal primer değerlendirildiğinde örneklerin büyük bir bölümünden obligat $B$. aphidicola elde edilmiş az sayıda fakültatif endosimbiyont türleri elde edilmiştir. Literatürde bu primer çifti farklı yaprakbitlerinde $B$. aphidicola'yı saptamak için kullanılırken yaprakbitlerinde diğer endosimbiyont türlerin saptandığı bir çalışmaya rastlanmamıştır. Ancak, bu primer çiftiyle Diaphorina citri Kuwayama (Hemiptera: Psyllida:)'de syncytium endosimbiyont ve Wolbachia endosimbiyontları belirlenmiştir (Marutani-Hert 2011). Başka bir çalışmada bu primer çiftinin Bacillus thuringiensis strainlerinde tüm 16S rDNA bölgesini elde etmede kullanıldığı görülmektedir (Shojaaddini ve ark. 2012). Bu nedenlerden dolayı farklı türler bu çalışmada elde edilmiş olabilir. B. aphidicola elde edilmeyen örneklerde bu türün olmadığı anlamına gelmemekte olup bu örneklerde ekolojik nedenlerle diğer endosimbiyont türlerin daha fazla var olmasından dolayı öne çıktığı düşünülmektedir.

Yaprakbitlerinde bulunan endosimbiyontlar, yaprakbitidoğal düşman, yaprakbiti-konukçu bitki ve diş koşullara adaptasyona yönelik yapılan çalışmalarda göz ard1 edilmemelidir. Yapılan son çalışmalar göstermiştir ki yaprakbitlerinin biyolojileri düşünülenden daha fazla endosimbiyontlarla ilișkilidir. $\mathrm{Bu}$ nedenle bir bölgede bir zararlıyı araştırırken ve mücadeleye karar verirken sadece zararlı değil ayrıca endosimbiyontlarıda göz önünde bulundurmakta yarar vardır.

\section{Teşekkür}

$\mathrm{Bu}$ çalışma Çukurova Üniversitesi BAP birimi (Proje No: FBA-2017-8202) tarafindan desteklenmiştir. Çalışmada yaprakbitlerinin morfolojik teşhislerini yapan Dr. Iş1 ÖZDEMIR'e teşekkür ederim.

\section{Kaynaklar}

Akman Gündüz E, Douglas AE (2008) Symbiotic bacteria enable insect to use a nutritionally inadequate diet. Proceedings of the Royal Society B: Biological Sciences 276(1658): 987-991.

Asplen MK, Bano N, Brady CM, Desneux N, Hopper KR, Malouines C, Oliver KM, White JA, Heimpel GE (2014) Specialisation of bacterial endosymbionts that protect aphids from parasitoids. Ecological Entomology 39(6): 736-739.

Baldo 1, Dunning Hotopp JC, Jolley KA, Bordensteîn SR, Biber SA, Choudhury RR, Hayashi C, Maiden MC, Tet-Telin H, Werren JH (2006) Multilocus sequence typing system for the endosymbiont Wolbachia pipientis. Applied and Environmental Microbiology 72: 7098-7110.

Baumann P, Baumann L, Lai CY, Rouhbakhsh D, Moran NA, Clark MA (1995) Genetics, physiology, and evolutionary relationships of the genus Buchnera: intracellular symbionts of aphids. Annual Review of Microbiology 49: 55-94.

Blackman RL, Eastop VF (2018) Aphids on the World's Plants: An Online Identification and Information Guide. Available from: http://www.aphidsonworldsplants.info. Erişim 19 Aralık 2019.

Brady CM, White JA (2013) Cowpea aphid (Aphis craccivora) associated with different host plants has different facultative endosymbionts. Ecological Entomology 38(4): 433-437.

Brady CM, Asplen MK, Desneux N, Heimpel GE, Hopper KR, Linnen CR, Oliver KM, Wulff JA, White JA (2014) Worldwide populations of the aphid Aphis craccivora are infected with diverse facultative bacterial symbionts. Microbial Ecology 67(1): 195-204. 
Burke GR, Normark BB, Favret C, Moran NA (2009) Evolution and diversity of facultative symbionts from the aphid subfamily Lachninae. Appliede. Environmental Microbiology 75(16): 53285335.

Chen DQ, Montllor CB, Purcell AH (2000) Fitness effects of two facultative endosymbiotic bacteria on the pea aphid, Acyrthosiphon pisum, and the blue alfalfa aphid, A. kondoi. Entomologia Experimentalis et Applicata 95(3): 315-323.

Chen CY, Lai CY, Kuo MH (2009) Temperature effect on the growth of Buchnera endosymbiont in Aphis craccivora (Hemiptera: Aphididae). Symbiosis 49: 53-59.

Degnan PH, Yu Y, Sisneros N, Wing RA, Moran NA (2009) Hamiltonella defensa, genome evolution of protective bacterial endosymbiont from pathogenic ancestors. Proceedings of the National Academy of Sciences 106(22): 9063-9068.

Degnan, PH, Leonardo TE, Cass BN, Hurwitz B, Stern D, Gibbs RA, Richards S, Moran NA (2010) Dynamics of genome evolution in facultative symbionts of aphids. Environmental Microbiology 12(8): 2060-2069.

Douglas AE (1998) Nutritional Interactions in Insect-Microbial Symbioses: Aphids and Their Symbiotic Bacteria Buchnera. Annual Review of Entomology 43: 17-37.

Favret C (2018) Aphid Species File, Version 5.0/5.0. Available from: http://Aphid.SpeciesFile.org. Erişim 19 Kasım 2019.

Felsenstein J (1985) Confidence limits on phylogenies: An approach using the bootstrap. Evolution 39: 783-791.

Fukatsu T (2001) Secondary Intracellular Symbiotic Bacteria in Aphids of the Genus Yamatocallis (Homoptera: Aphididae: Drepanosiphinae). Applied Environmental Microbiology 67: 53155320.

Liu L, Huang X, Zhang R, Jiang L, Qiao G (2013) Phylogenetic congruence between Mollitrichosiphum (Aphididae: Greenideinae) and Buchnera indicates insect-bacteria parallel evolution. Systematic Entomology 38: 81-92.

Martine AJ, Weldon SR, Oliver KM (2013) Effects of parasitism on aphid nutritional and protective symbioses. Molecular Ecology 23(6): 1594-1607.

Marutani-Hert M, Hunter WB, Morgan JK (2011) Associated bacteria of Asian citrus psyllid (Hemiptera: Psyllidae: Diaphorina citri). Southwestern Entomologist 36(3): 323-331.

Munson MA, Baumann P, Clark MA, Baumann L, Moran NA, Voegtlin DJ, Campbell BC (1991) Aphid-eubacterial endosymbiosis: Evidence for its establishment in an ancestor of four aphid families. Journal of Bacteriology 173: 6321-6324.

Nei M, Kumar S (2000) Molecular Evolution and Phylogenetics. Oxford University Press, New York.

Nikoh N, McCutcheon JP, Kudo T, Miyagishima SY, Moran NA, Nakabachi A (2010) Bacterial genes in the aphid genome: Absence of functional gene transfer from Buchnera to its host. PLoS Genetic 6: 18-21.

Patel V, Chevignon G, Manzano-Marín A, Brandt JW, Strand MR, Russell JA, Oliver KM (2019) Cultivation-Assisted Genome of Candidatus Fukatsuia symbiotica; the Enigmatic "X-Type" Symbiont of Aphids. Genome Biology and Evolution 11(12): 35103522 .
Peccoud J, Bonhomme J, Mahéo F, de la Huerta M, Cosson O, Simon JC (2013) Inheritance patterns of secondary symbionts during sexual reproduction of pea aphid biotypes. Insect Science 1-10.

Pe'rez-Brocal V, Gil R, Ramos S, Lamelas A, Postigo M, Michelena JM, Silva FJ, Moya A, Latorre A (2006) A small microbial genome: The end of a long symbiotic relationship?. Science 314: 312-313.

Prado S, Jandricic S, Frank S (2015) Ecological interactions affecting the efficacy of Aphidius colemani in greenhouse crops. Insects 6(2): 538-575.

Russell JA, Moran NA (2006) Costs and benefits of symbiont infection in aphids: Variation among symbionts and across temperatures. Proceedings: Biological Sciences 273(1586): 603-610.

Satar S, Satar G, Karacaoğlu M, Uygun N, Kavallieratos NG, Starý P, Athanassiou CG (2014) Parasitoids and hyperparasitoids (Hymenoptera) on aphids (Hemiptera) infesting citrus in east Mediterranean region of Turkey. Journal of Insect Science 14: 178.

Satar G (2019) Phylogenetic of Buchnera aphidicola Munson et al., 1991 based on 16S rRNA amplified from seven aphid species. Türkiye Entomoloji Dergisi 43(2): 227-237.

Satar G, Karacaoğlu M, Uygun N, Satar S (2019) Some Demographic Parameters of Lysiphlebus confusus, L. fabarum, and L. testaceipes (Hymenoptera: Braconidae: Aphidiinae). Journal of Economic Entomology 112(3): 1105-1111.

Shojaaddini M, López MJ, Moharramipour S, Khodabandeh M, Talebi AA, Vilanova C, Latorre A, Porcar M (2012) A Bacillus thuringiensis strain producing epizootics on Plodia interpunctella: a case study. Journal of Stored Products Research 48: 52-60.

Simon JC, Boutin S, Tsuchida T, Koga R, Le Gallic J-F, Frantz A, Fukatsu T (2011) Facultative symbiont infections affect aphid reproduction. PloS One 6(7): 1-10.

Tamura K, Stecher G, Peterson D, Filipski A, Kumar S (2013) MEGA6: Molecular Evolutionary Genetics Analysis version 6.0. Molecular Biology and Evolution 30: 2725-2729.

Telesnicki MC, Ghersa CM, Martínez-Ghersa MA, Arneodo JD (2012) Molecular identification of the secondary endosymbiont Hamiltonella defensa in the rose-grain aphid Metopolophium dirhodum. Revista Argentina de Microbiología 44(4): 255-258.

Tian PP, Chang CY, Miao NH, Li MY, Liu XD (2019) Infections with Arsenophonus Facultative Endosymbionts Alter Performance of Aphids (Aphis gossypii) on an Amino-Acid-Deficient Diet. Applied and Environmental Microbiology 85(23).

Tsuchida T, Koga R, Horikawa M, Tsunoda T, Maoka T, Matsumoto S, Simon JC, Fukatsu T (2010) Symbiotic bacterium modifies aphid body color. Science 330(6007): 1102-1104.

Uygun N, Toros S, Ulusoy R, Satar S, Özdemir I (2001) Doğu Akdeniz Bölgesi Aphidoidea (Homoptera) türleri ile bunların parazitoid ve predatörlerinin saptanması. TUBİTAK, Proje no: 105-O-581.

Vorburger C, Gehrer L, Rodriguez PA (2010) A strain of the bacterial symbiont Regiella insecticola protects aphids against parasitoids. Biology Letters 109-111.

Wulff JA, White JA (2015) The endosymbiont Arsenophonus provides a general benefit to soybean aphid (Hemiptera: Aphididae) regardless of host plant resistance (Rag). Environmental Entomology 44(3): 574-581. 